\title{
Age-related increases in parathyroid hormone may be antecedent to both osteoporosis and dementia
}

\author{
Eric R Braverman 1,8, Thomas JH Chen², Amanda LC Chen ${ }^{3}$, Vanessa Arcuri ${ }^{4}$, \\ Mallory M Kerner ${ }^{4}$, Anish Bajaj ${ }^{4}$, Javier Carbajal ${ }^{4}$, Dasha Braverman ${ }^{4}$, B \\ William Downs ${ }^{5}$ and Kenneth Blum*4,5,6,7
}

\begin{abstract}
Address: ${ }^{1}$ Department of Neurological Surgery, Weill Cornell College of Medicine, New York, New York, USA, ${ }^{2}$ Department of Health and Occupational Safetly, Chang Jung Christian University, Taiwan, Republic Of China, ${ }^{3}$ Department of Engineering, Chang Jung Christian University, Taiwan, Republic Of China, ${ }^{4}$ Department of Neurological Research, Path Research Foundation, New York, NY, USA, ${ }^{5}$ Department of Molecular Nutrition \& Nutrigenomics, LifeGen, Inc La Jolla, California, USA, ${ }^{\circ}$ Department of Physiology and Pharmacology, Wake Forest University School of Medicine, Winston -Salem, NC, USA, ${ }^{7}$ Department of Psychiatry, School of Medicine, University of Florida, Gainesville, FL, USA and ${ }^{8}$ Path Medical Research Foundation, 304 Park Ave South, 6th Floor, NY, NY 10010, USA

Email: Eric R Braverman - pathmedical@aol.com; Thomas JH Chen - tjhchen@yahoo.com.tw; Amanda LC Chen - tjhchen@yahoo.com.tw; Vanessa Arcuri - vanessaarcuri@yahoo.com; Mallory M Kerner - mallory.kerner@gmail.com; Anish Bajaj - dranishbajaj@gmail.com; Javier Carbajal - javi64shoebox@aol.com; Dasha Braverman - dasha@totalhealthnutrients.com; B William Downs - billdowns001@comcast.net; Kenneth Blum* - drd2gene@aol.com

* Corresponding author
\end{abstract}

Published: 13 October 2009

BMC Endocrine Disorders 2009, 9:21 doi:10.1186/1472-6823-9-2।

This article is available from: http://www.biomedcentral.com//472-6823/9/2I

(C) 2009 Braverman et al; licensee BioMed Central Ltd.

This is an Open Access article distributed under the terms of the Creative Commons Attribution License (http://creativecommons.org/licenses/by/2.0), which permits unrestricted use, distribution, and reproduction in any medium, provided the original work is properly cited.

\begin{abstract}
Background: Numerous studies have reported that age-induced increased parathyroid hormone plasma levels are associated with cognitive decline and dementia. Little is known about the correlation that may exist between neurological processing speed, cognition and bone density in cases of hyperparathyroidism. Thus, we decided to determine if parathyroid hormone levels correlate to processing speed and/or bone density.

Methods: The recruited subjects that met the inclusion criteria $(n=92$, age-matched, age 18-90 years, mean $=$ $58.85, S D=15.47$ ) were evaluated for plasma parathyroid hormone levels and these levels were statistically correlated with event-related P300 potentials. Groups were compared for age, bone density and P300 latency. One-tailed tests were used to ascertain the statistical significance of the correlations. The study groups were categorized and analyzed for differences of parathyroid hormone levels: parathyroid hormone levels $<30(n=30$, mean $=22.7 \pm 5.6 \mathrm{SD})$ and PTH levels $>30(n=62$, mean $=62.4 \pm 28.3 \mathrm{SD}, \mathrm{p} \leq 02)$.

Results: Patients with parathyroid hormone levels $<30$ showed statistically significantly less P300 latency (P300 $=332.7 \pm 4.8 \mathrm{SE}$ ) relative to those with parathyroid hormone levels $>30$, which demonstrated greater $\mathrm{P} 300$ latency $(P 300=345.7 \pm 3.6 \mathrm{SE}, \mathrm{P}=.02)$. Participants with parathyroid hormone values $<30(n=26)$ were found to have statistically significantly higher bone density $(M=-1.25 \pm .3 \mathrm{I} \mathrm{SE})$ than those with parathyroid hormone values $>30(n=48, M=-1.85 \pm .19 \mathrm{SE}, \mathrm{p}=.04)$.

Conclusion: Our findings of a statistically lower bone density and prolonged P300 in patients with high parathyroid hormone levels may suggest that increased parathyroid hormone levels coupled with prolonged P300 latency may become putative biological markers of both dementia and osteoporosis and warrant intensive investigation.
\end{abstract}




\section{Background}

While numerous studies have reported that age-induced increased parathyroid hormone (PTH) plasma levels are associated with cognitive decline [1] and dementia [2,3], little is known about the correlation that may exist between neurological processing speed and bone density in cases of hyperparathyroidism or elevated PTH. The latency of the P300 auditory evoked potential (which measures processing speed and has been shown to accurately predict memory impairment [4]) has only been studied with PTH levels in chronic renal failure, and the last work on this topic, to our knowledge, was published in 1983 [5].

PTH is anabolic in bone, but when secreted in excess it is catabolic [6]. Its levels increase with age in both genders, paralleling the incidence of osteopenia and osteopososis [7]. Recombinant human PTH 1-34 (teriparatide) is now being used as a treatment for osteoporosis, and its administration has been shown to stimulate bone formation and increase bone mineral density [8]. Interestingly, it has recently been discovered that intermittent administration of teriparatide inhibits endogenous PTH production [9], possibly via negative feedback. So far, there has not yet been any published research on teriparatide administration for hyperparathyroidism-induced osteoporosis.

Our greater understanding of PTH has led to lowering of the reference ranges. In 2003, the American Kidney Foundation recommended that levels should be kept between 35 and $70 \mathrm{pg} / \mathrm{ml}$ [10] for stage 3 chronic kidney disease, which is characterized by a glomerular filtration rate (GFR) of $30-59 \mathrm{~mL} / \mathrm{min} / 1.73 \mathrm{~m}^{2}$, and that an estimated $7.7 \%$ of the population suffers [11]. Currently, the acceptable reference range for parathyroid hormone (PTH) is between 10 and $60 \mathrm{pg} / \mathrm{mL}$. It has been suggested that, where there is normal renal function and elevated serum calcium, an intact PTH concentration of $>50 \mathrm{pg} / \mathrm{mL}$ strongly suggests primary hyperparathyroidism [12]. It is well established that hyperparathyroidism is responsible for changes in bone metabolism leading to a reduction in bone mineral density [13], and the National Osteoporosis Foundation lists hyperparathyroidism as a risk factor for osteoporosis [14].

The P300 wave is an event related potential that can be recorded via electroencephalograph (EEG) as a positive deflection in voltage at a latency of roughly $300+$ age milliseconds [4]. The presence, magnitude, topography, and time of this signal can measure and describe processing speed. Prolonged P300 latency is an antecedent to memory loss and cognitive decline [4]. Since hyperparathyroidism has already been associated with cognitive decline [1-3], and increased P300 latency is an early measure and a better predictor of preclinical dementia than memory or mental status tests [4], we decided to determine if PTH levels correlate to processing speed and/or bone density.

\section{Methods \\ Participants}

The sample consisted of 95 patients from PATH Medical, an integrative care center and research foundation. Ages ranged between 18 and 90 years, with a mean of $M=$ $58.85, S D=15.47$. We started with age 18 because many individuals enter adulthood with poor bone density. Furthermore, osteoporosis is considered to be a childhood disease, in that childhood and adolescence are the times when peak bone mass is established [15,16]. Missing data reduced the sample size for $\mathrm{P} 300$ speed of processing (P300SP) and P300 voltage (P300V) to 92. For Bone Mineral Density (BMD), missing data reduced the sample size to 74. Forty (forty-two percent) were male and fifty-six (fifty-eight percent) were female. All patients signed an approved IRB consent form based on an approval from the PATH Research Foundation IRB committee (registration \# IRB00002334). Patients were made aware that their results could be used in medical research and by signing the informed consent, they volunteered to participate in this study.

In this study, analysis was conducted only on patients with complete data, $(\mathrm{n}=92$, age-matched, age 18-90 years, mean $=58.85, S D=15.47)$, including measurement of intact serum PTH levels (BioReference Laboratories) between 9 AM and 3 PM, BMD, and neurological processing speed as determined by P300 latency. The P300 wave is an event-related potential that can be recorded via electroencephalograph (EEG) as a positive deflection in voltage at a latency of roughly $300 \mathrm{msec}$. We have found in previous research that the $\mathrm{P} 300$ wave is an accurate predictor of cognitive decline [4], and the "reference" range for P300 latency is roughly $300+$ age msec. In this study, groups were categorized by patients with: PTH levels $<30$ $(\mathrm{n}=30$, mean $=22.7 \pm 5.6 \mathrm{SD})$ and PTH levels $>30(\mathrm{n}=$ 62 , mean $=62.4 \pm 28.3 \mathrm{SD}, \mathrm{p} \leq .02$ ). We used a Hologic Dual-Energy X-Ray Absorptiometry (DEXA) machine to measure $\mathrm{BMD}$, focusing on the lumbar vertebrae and the left hip for all participants. Groups were compared for age, BMD and P300 latency.

\section{Statistical Analysis}

One-tailed tests were used to ascertain the statistical significance of the correlations. The statistical analysis of the data was conducted in four phases. First, the PTH measure was dichotomized, with PTH values below 30 categorized as $1($ low), and PTH values above 30 categorized as 2 (high). We used 30 as the cutoff since it is close to but slightly lower than the midpoint of the current reference range (35) [12], and since 30 is clearly well below the cur- 
rent risk range which is not yet well defined. This step was taken to test the statistical significance of differences in P300SP, P300V and BMD between low and high levels of PTH. In addition, the BMD measure was dichotomized using a median $(M d)$ split procedure $(M d=-1.88)$, with $\mathrm{BMD}$ values equal to or lower than $M d$ categorized as 1 (low), and values greater than $M d$ categorized as 2 (high). This step was taken to test the statistical significance of differences in P300SP and P300V, between low and high levels of BMD.

The second phase of the analysis of the data involved the calculation of the q-test of normality for P300SP, P300V, $\mathrm{BMD}$ and age. This test was conducted to determine whether parametric or non-parametric tests of significance should be used to examine differences between the high and low levels of PTH on P300SP, P300V and BMD-and between the high and low levels of BMD on P300SP and P300V. A test of normality was also conducted for PTH.

The $q$-test is calculated by dividing the sample's standard deviation by the sample's range. The obtained $q$ statistic is compared against a given range for the sample size at hand, and a $q$ value falling within this range, derived on the basis of a .025 significance level [17] is interpreted as indicative that the sample distribution does not depart statistically significantly from normality. A table due to Sachs (1984) [18] provides critical ranges of values for varying sample sizes. For the present sample size of 95 for age, the $q$ span, ranged between 4.17 and 6.07; for the P300SP and P300V sample size of 92, it ranged between 4.15 and 6.05; and for BMD's sample size of 74, it ranged between 4 and 5.87 .

The third phase of the analysis of the data involved the calculation of the correlations among age, BMD, PTH, P300SP, and P300V.

The fourth phase of the analysis of the data involved the calculation of tests of statistical significance using the dichotomized PTH measure as the independent variable and P300SP, P300V, BMD, and age as dependent variables. Tests of statistical significance were also calculated using the dichotomized BMD measure as the independent variable and P300SP and P300V as the dependent variables. The effect sizes (ES) of the categorized PTH and BMD measures were calculated to ascertain the strength of association between the categorized independent and the dependent variables. Effect size is calculated as

$$
E S=\left[\left(t^{2} /\left(t^{2}+d f\right)\right]^{1 / 2} .\right.
$$

An ES equal to or higher than .20 is considered empirically consequential.

\section{Results}

The following paragraphs describe the outcomes of the tests of normality, the correlational analyses, and the analyses of differences between the levels of the dichotomized forms of PTH and BMD.

\section{Tests of Normality}

Figure 1 displays the distributions of P300SP, figure 2 displays the distributions of P300V, figure 3 displays the distributions of $\mathrm{BMD}$, and figure 4 displays the distributions of age. For P300SP, P300V, BMD and age, the distributions tended to approach symmetry, suggesting further, more formal testing for normality by means of the $q$-test.

Table 1 displays the q-test outcomes. As shown in this table, the q value of P300SP was 6.02, that for P300V was 5.23 , and that for age was 5.04--all falling within the normality range for $\mathrm{n}=92$ of 4.15 to 6.05 . For BMD, it was 5.54 , falling within the normality range for $\mathrm{n}=74$ of 4 to 5.87. The $\mathrm{q}$ value for PTH was 6.38 , falling outside the 4.17 to 6.07 normality range for $n=95$. These outcomes supported the assumption of normality required for the use of parametric tests in the case of P300SP, P300V, $\mathrm{BMD}$, and age, and hence, the Pearson correlation coefficient was used to calculate the level of relation among the variables in continuous form, and the t-test was used to ascertain the statistical significance of the differences between the two categories of PTH on P300SP, P300V, BMD. Since the hypotheses were stated unidirectionally, one-tailed tests were used; alpha (a) was set at the .05 level.

\section{Pearson Correlation Coefficients}

Table 2 displays the Pearson correlation coefficients. In this table, BMD and PTH appear in both continuous and dichotomized form. As evidenced by the outcomes shown in this table, age proved to be statistically significantly correlated with PTH, P300SP, and P300V; BMD proved to be statistically significantly correlated with PTH in dichotomized form; BMD in dichotomized form proved to be statistically significantly correlated with P300V; PTH proved to be statistically significantly correlated with P300P; and P300SP proved to be statistically significantly correlated with P300V.

The following tables depict the $t$-test outcomes. They show the means, standard deviations and standard errors of the dependent variables for each category of the independent variables, and show the $t$-statistics, $p$-values, and effects sizes.

Table 3 displays the $t$-test outcomes of P300SP by PTH in categorized form. As shown in this table, the P300SP mean of the low category of PTH $(M=332.66, S D=6.39)$ proved to be statistically significantly lower than that of 


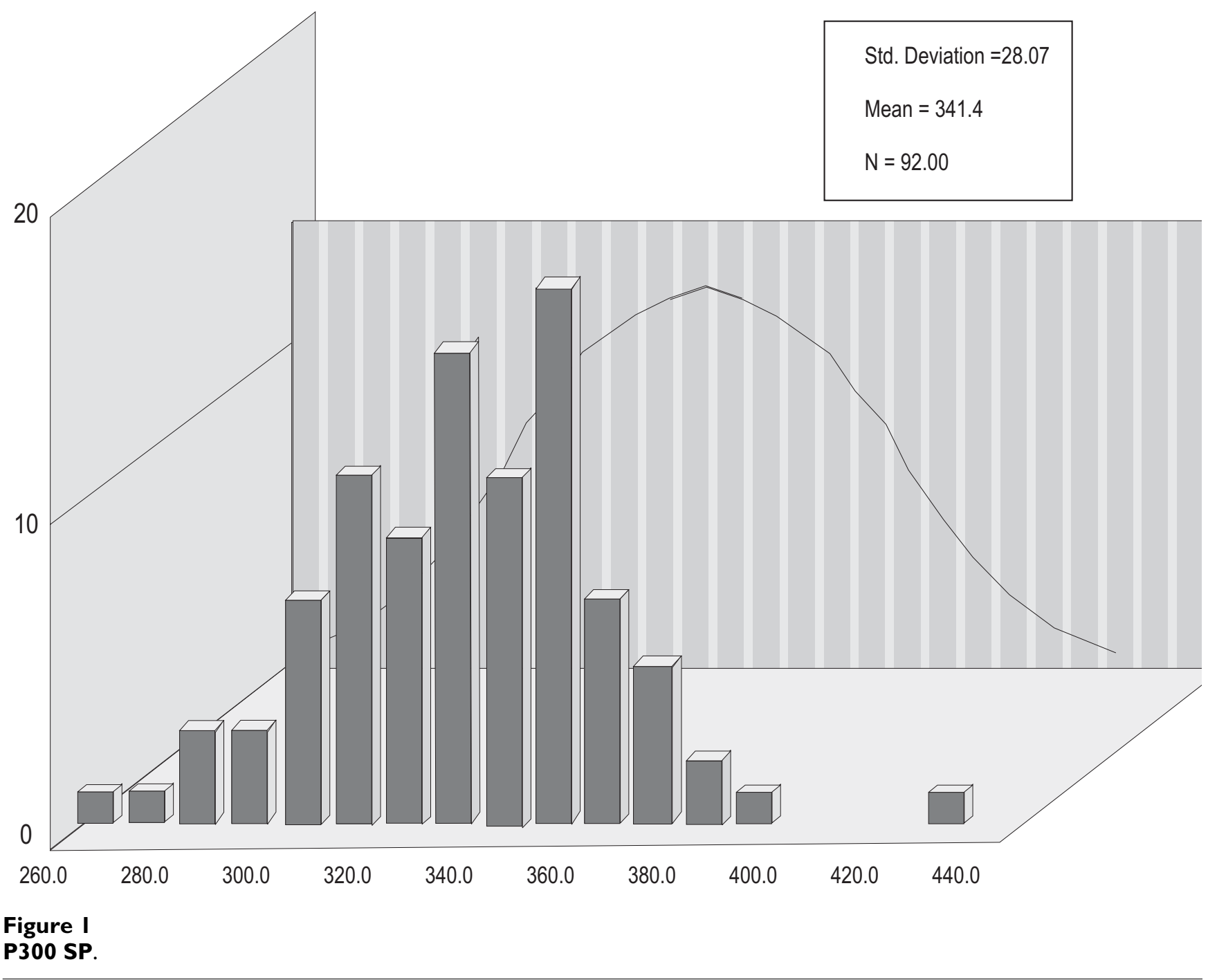

the high PTH category $(M=345.68, S D=28.08), t=-2.12$, $d f=90, p=.02$ (1-tail test). The effect size was $E S=.22--$ an effect which, being greater than .20 , proved to have practical significance according to criteria propounded by Cohen [19] and Kirk [20].

These findings disclosed that level of PTH is positively associated with level of $\mathrm{P} 300 \mathrm{P}$, and that the strength of the association is of practical importance. The implications of these findings are discussed below.

Table 4 displays the $t$-test outcomes of P300V by PTH in categorized form. As shown in this table, the P300V mean of the low category of PTH $(M=5.27, S D=3.15)$ did not differ statistically significantly from that of the high PTH category $(M=5.28, S D=2.39), t=-.028, d f=5.31, p=.49$ (1-tail test). The effect size was $E S=.03$, showing a null effect of PTH on P300V. These findings disclosed a lack of association between PTH and P300V levels. The implications of these findings are also discussed below.

Table 5 displays the $t$-test outcomes of BMD by PTH in categorized form. As shown in this table, the mean BMD score of participants in the low category of PTH $(M=-$ $1.25, S D=1.57$ ) differed statistically significantly from that of participants in the high PTH category $(M=-1.85$, $S D=1.28), t=1.77, d f=72, p=.04$ (1-tail test). The effect size was $E S=.20$, showing a substantive effect of PTH on BMD in terms of criteria propounded by [19] and [20]. These findings disclosed an empirically important association between levels of PTH and levels of BMD. The implications of these findings are also discussed below.

Table 6 displays the $t$-test outcomes for P300SP by BMD in categorized form. As shown in this table, the mean age of participants in the low category of BMD $(M=344.18$, 


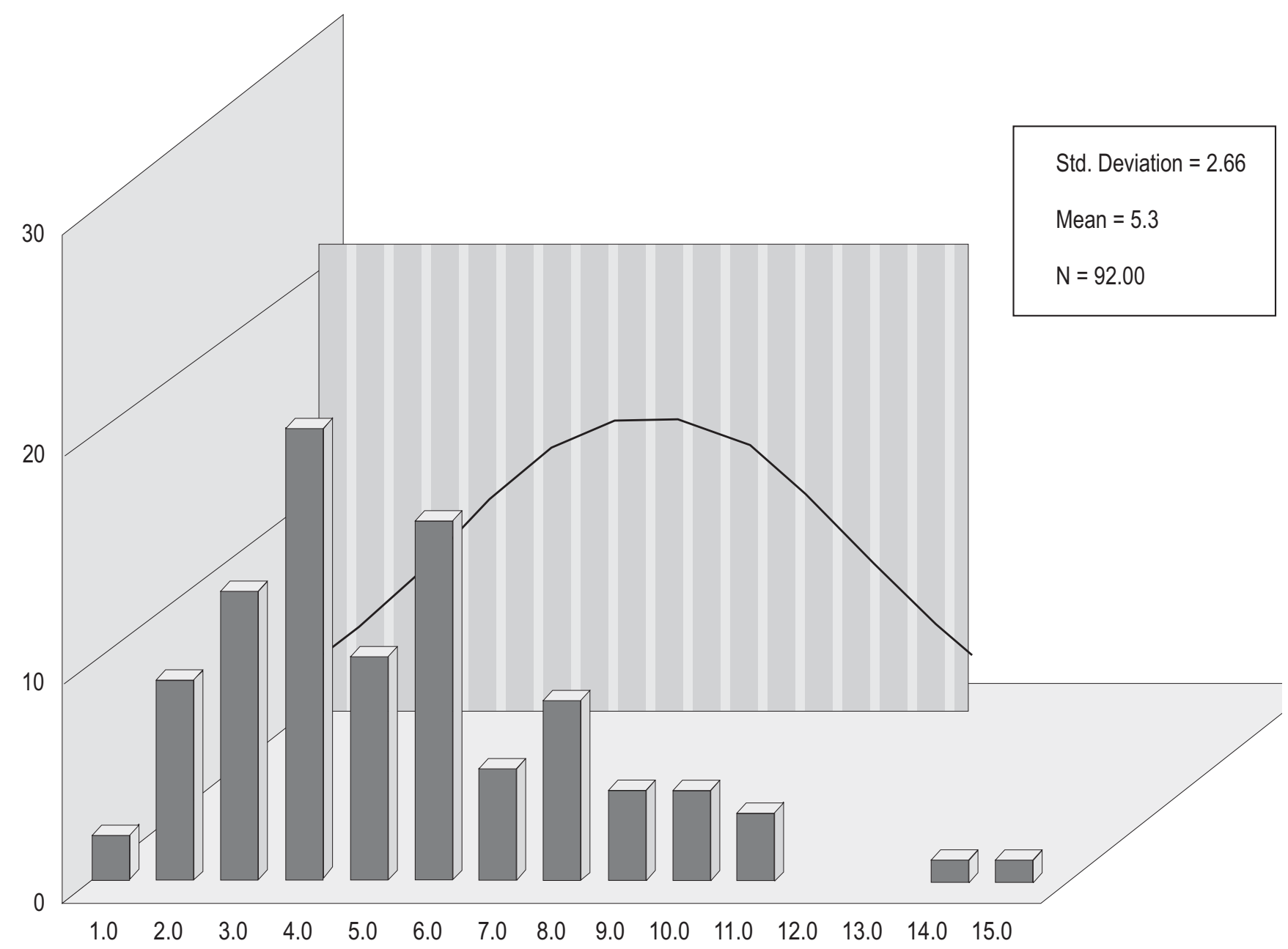

Figure 2

P300 V.

$S D=30.40)$ did not differ statistically significantly from that of participants in the high PTH category $(M=341.99$, $S D=21.48), t=.35, d f=70, p=.36$ (1-tail test). The effect size was $E S=.04$--an effect which, being lower than .20 , proved to have insubstantial practical significance according to criteria propounded by [19] and [20]. This effect was the same as the Pearson correlation coefficient of P300SP with the original categorized BMD scores $(r=-$ $.04, p>.05)$. The implications of these findings are also discussed below.

Table 7 displays the $t$-test outcomes for P300V by BMD in categorized form. As shown in this table, the mean age of participants in the low category of BMD $(M=5.80, S D=$ 2.83) differed statistically significantly from that of participants in the high BMD category $(M=4.38, S D=13.66)$, $t=2.46, d f=70, p=.005$ (1-tail test). The effect size was $E S=.28$--an effect which, being greater than .20 , proved to have practical significance. This effect was the same as the Pearson correlation coefficient of P300SP with the original categorized BMD scores $(r=.-28, p=.008)$. The implications of these findings are also discussed below.

Finally, table 8 displays the means, standard deviations and standard errors of the two PTH categories. As shown in this table, the two categories' means differed substantially: category 1 (low): $M=22.65$; category 2 (high): 62.37 .

\section{Discussion}

Our findings suggest that age dependent prolonged P300 latency, as well as age dependent increased PTH levels, may interact. This is a timely discovery since there has been a recent influx of research highlighting the connections between the brain and the bones, and a new field has been birthed called neuropsychosteology [21,22]. 


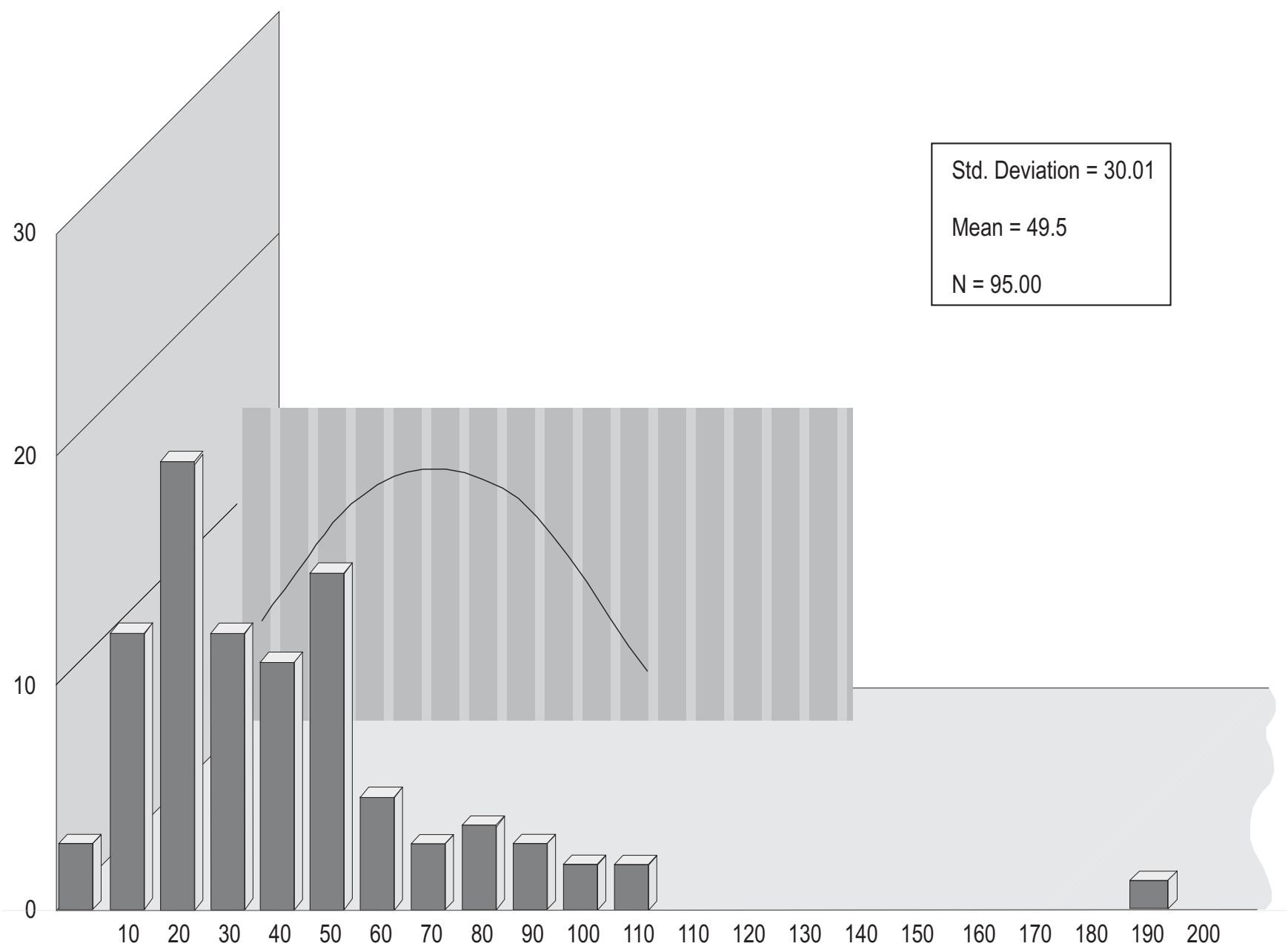

Figure 3

BMD.

Many studies have confirmed neuropsychiatric disease increases with osteoporosis (OP) [23-25].

Our measurement of PTH did not take into account factors that could affect analysis: age, gender, menopausal status, vitamin D and calcium supplementation, smoking, alcohol consumption, steroid use, family history of osteoporosis, physical activity, drugs to control bone and calcium metabolism, rheumatoid arthritis, other diseases that cause secondary osteoporosis, levels of sex hormones, etc. Further studies will be needed to clarify all of these variables in relation to PTH's effects on the aging brain and aging skeleton.

Based on our findings, we suggest that control of PTH levels may be important for protecting against age-induced dementia. PTH's potential involvement with dementia may be explained in the following way: PTH has been shown to cross the blood-brain barrier [26]. PTH has been considered a candidate risk factor for senile dementia because sustained high levels of PTH in the brain may cause degeneration of specific brain regions due to $\mathrm{Ca}(2+)$ overloading $[27,28]$.

Moreover, OP is a genetic disease and as such the role of 1,25-dihydroxyvitamin $\mathrm{D}_{3}$-receptor gene polymorphisms, known OP genetic antecedents [29] may contribute in some way to the age-linked impairments in both parathyroid and neurological processing function. It is to be noted that PTH tides are of short duration while Vitamin $\mathrm{D}$ or calcitriol tides are of long duration. PTH quickly mobilizes bone calcium, while calcitriol tends to more slowly increase the absorption of dietary calcium. In the case of low or no dietary calcium, calcitriol mobilizes bone calcium together with PTH. Because of this, mixed effects occur during Vitamin D deficiency, and pseudo- or 


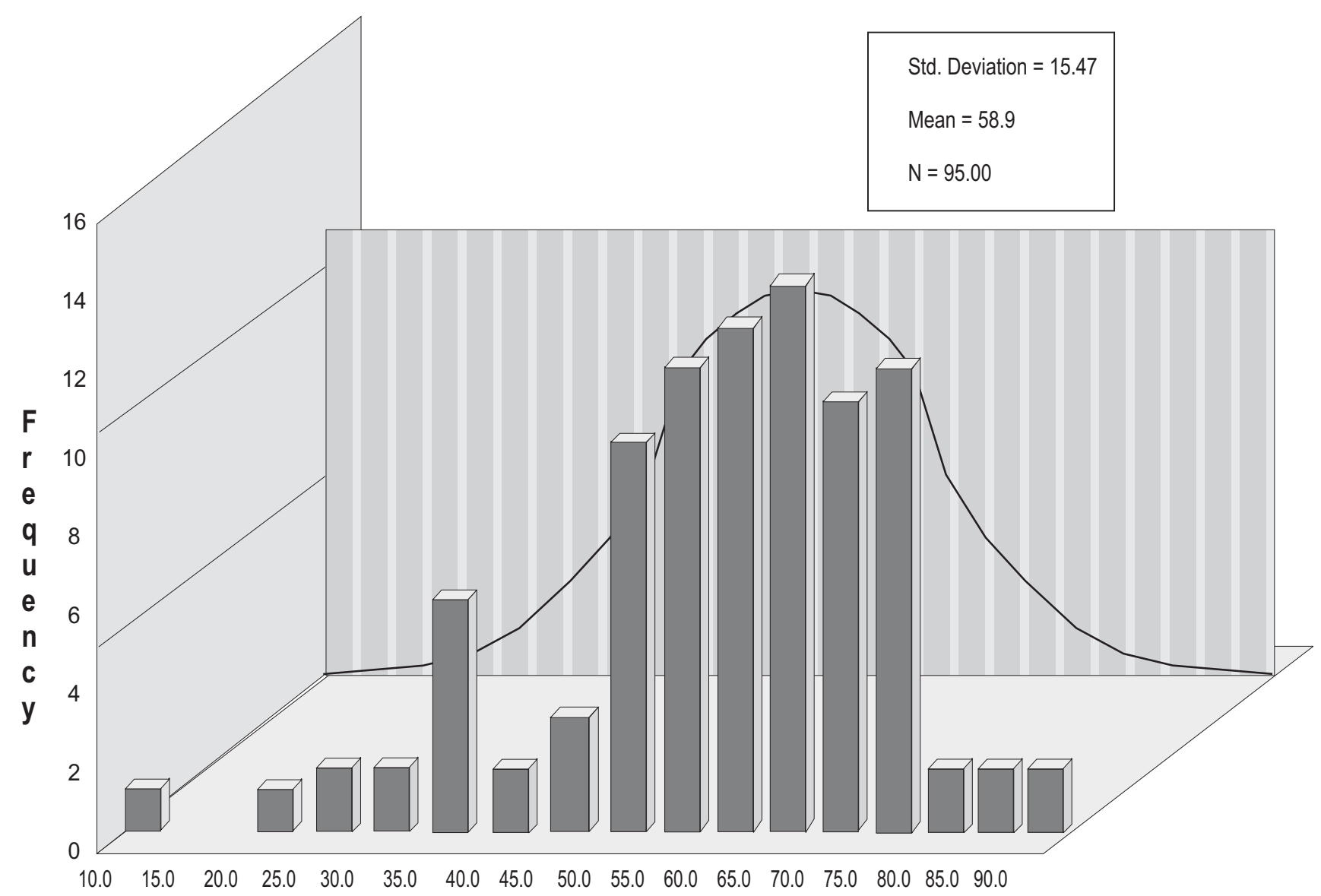

Figure 4

Age.

secondary hyperparathyroid conditions occur. Furthermore, overnight fasting with reduced absorption of dietary calcium associated with age results in a regulatory set point inducing an increase of PTH secretion with age[30].

It is apparent that PTH levels should be kept below 60 pg/ $\mathrm{ml}$, and we believe based on our findings that these levels may be lowered still. Further research should involve

Table I: q-Tests for Normality of Distribution.

\begin{tabular}{cccccc}
\hline & \multicolumn{5}{c}{ Variables } \\
\cline { 2 - 6 } Statistics & P300SP & P300V & BMD & PTH & Age \\
\hline SD & 28.07 & 2.66 & 1.41 & 30.01 & 15.47 \\
Range & 169 & 13.93 & 7.82 & 191 & 78 \\
$\mathbf{q}$ & 6.02 & 5.23 & 5.54 & 6.37 & 5.04
\end{tabular}

The q range for normality for a sample size of 93 , as was the case for P300SP, P300V, PTH, and Age, is 4.16 to 6.07 with a significance level of .025. For a sample size of 74 , as was the case for Bone density, the q range is 4 to 5.87 , also with a significance level of .025 .
P300 latency testing for a larger number of patients and stratification by age, and correlating PTH levels and BMD. This study provides the first potential indirect evidence that may highlight the importance of processing speed as an early electrophysiological marker of OP, which warrants further investigation.

Table 2: Correlation Matrix.

\begin{tabular}{|c|c|c|c|c|c|c|c|}
\hline & $I$ & 2 & 3 & 4 & 5 & 6 & 7 \\
\hline I. Age & 1 & & & & & & \\
\hline 2. BMD & .03 & I & & & & & \\
\hline 3. BMD' & .01 & $.62^{*}$ & 1 & & & & \\
\hline 4. PTH & $.22 *$ & -.04 & -.03 & I & & & \\
\hline 5. $\mathrm{PTH}^{2}$ & $.21^{*}$ & $-.21 *$ & -.11 & $.62^{*}$ & I & & \\
\hline 6. P300SP & $.40 *$ & -.07 & -.04 & $.18^{*}$ & $.22 *$ & I & \\
\hline 7. P300V & $-.18^{*}$ & -.15 & $-.28^{*}$ & -.06 & .00 & $-.19 *$ & I \\
\hline
\end{tabular}

IDichotomized ( $\mid<=-1.88 ; 1.88 ; 2>-t-T e s t$ Outcomes- 1.88$)$

2Dichotomized ( $<30 ; 2>30$ )

$\mathrm{P}<0.05$

'Dichotomized $(1<=-* p<.05$ 
Table 3: $t$-Test of the Difference in P300SP Between the Categories of PTH.

\begin{tabular}{cccccccccc}
\hline & \multicolumn{4}{c}{ P300SP } & \multicolumn{5}{c}{$t$-Test } \\
\cline { 2 - 8 } PTH & $\mathbf{N}$ & $\mathbf{M}$ & SD & SE & $T$ & Df & $\boldsymbol{P}$ & ES* \\
\hline I $(<30)$ & 30 & 332.66 & 26.39 & 4.81 & & & & \\
& & & & & -2.12 & 90 & .02 & .22 \\
$2(>30)$ & 62 & 345.68 & 28.08 & 3.57 & & & & \\
Total & 92 & 341.44 & 28.07 & 2.93 & & & & \\
\hline
\end{tabular}

*Effect size

Increases in PTH levels with age are major factors responsible for age-related increase in bone resorption, and contribute to kidney stone formation as well [31]. PTH levels need to be monitored in osteoporotic, memory-impaired people and lowering the levels may be an important part of the therapeutic process of teriparatide injections. At the PATH Medical Clinic, PTH levels were reduced by teriparatide injections by an average of 20 points, possibly due to a negative feedback mechanism. This is further supported by others [9]. Additional research has shown that teriparatide therapy may need to be supplemented by GH or GH-dependent factors in order for the anabolic response of bone [32,33].

Finally, the findings of this study showing a significant relationship between higher PTH plasma levels and prolonged P300 latency as well as a decrease in BMD suggest that hyperparathyroidism and elevated PTH due in part to age may lead to dementia and OP. The connection between elevated PTH and cognitive decline is becoming well studied. A recent study published in the Journal of Clinical Endocrinology and Metabolism presented results of various cognitive testing in postmenopausal women with hyperparathyroidism, before and after parathyroidectomy, with pre-surgical cognitive impairments improving after surgery [33]. Further studies are warranted to confirm the value of increased PTH levels coupled with increased P300 latency as putative biological markers of both dementia and OP.

Table 4: $t$-Test of the Difference in P300V Between the Categories of PTH.

\begin{tabular}{ccccccccc}
\hline & \multicolumn{4}{c}{ P300V } & \multicolumn{5}{c}{$t$-Test } \\
\hline PTH & $\boldsymbol{N}$ & $\mathbf{M}$ & SD & SE & $\boldsymbol{T}$ & $\boldsymbol{d f}$ & $\boldsymbol{P}$ & $E^{*}$ \\
\hline $\mathrm{I}(<30)$ & 30 & 5.27 & 3.15 & .58 & & &. & \\
& & & & & 028 & 45.31 & .49 & .03 \\
$2(>30)$ & 62 & 5.28 & 2.39 & .30 & & & & \\
Total & 92 & 5.29 & 2.66 & .28 & & & & \\
\hline
\end{tabular}

*Effect size
Table 5: $t$-Test of the Difference in BMD Between the Categories of PTH.

\begin{tabular}{cccccccccc}
\hline & \multicolumn{3}{c}{ BMD } & \multicolumn{1}{c}{ t-Test } \\
\cline { 2 - 8 } PTH & $\mathbf{N}$ & $\mathbf{M}$ & SD & SE & $T$ & Df & $P$ & ES* \\
\hline I $(<30)$ & 26 & -1.25 & 1.57 & .31 & & & & \\
& & & & & 1.77 & 72 & .04 & .20 \\
$2(>30)$ & 48 & -1.85 & 1.28 & .19 & & & & \\
Total & 74 & -1.64 & 1.41 & .163 & & & & \\
\hline
\end{tabular}

*Effect size

\section{Conclusion}

Patients with PTH levels $<30$ showed statistically significantly lesser P300 latency $(\mathrm{P} 300=332.7 \pm 4.8 \mathrm{SE})$ relative to those with high PTH levels (>30), who demonstrated greater P300 latency $(\mathrm{P} 300=345.7 \pm 3.6 \mathrm{SE}, \mathrm{p}=.02)$. In addition, participants with PTH values $<30(\mathrm{n}=26)$ were found to have statistically significantly higher bone density $(M=-1.25 \pm .31 \mathrm{SE})$ than those with PTH values $>30$ $(\mathrm{n}=48, \mathrm{M}=-1.85 \pm .19 \mathrm{SE}, \mathrm{p}=.04)$

The relevance of this research is more far reaching than might be initially suspected. A healthy skeleton is more important to overall health than for just lowering fracture risk. Healthy bones are intimately involved as an endocrine organ performing many important functions including the production of red blood cells, immune cells, platelets, various growth factors, and cytokines [35]. Bone cells and immune stem cells have a common origin and a functional relationship called the "osteo-immune relationship [35-37]" Healthy bones also exert an endocrine regulation of sugar homeostasis, fat storage, energy metabolism, cognition and more [38]. These functional relationships are the basis for the growing field of osteoimmunology [35]. Moreover, chronic immune system overexertion is known to lead to bone loss, promote muscle wasting [35] and increase fat storage [38-41].

This research supports the notion that a strong relationship exists between bone health, brain health, neurological competence, endocrine function, immune health, and genetics, building potential therapeutic bridges across the

Table 6: $t$-Test of the Difference in P300SP Between the Categories of BMD.

\begin{tabular}{cccccccccc}
\hline & \multicolumn{10}{c}{ P300SP } \\
\cline { 2 - 8 } BMD & $\boldsymbol{N}$ & $\mathbf{M}$ & SD & SE & $\boldsymbol{t}$ & df & $\boldsymbol{P}$ & ES* \\
\hline I (<=-1.88) & 36 & 344.18 & 30.40 & 5.06 & & & & \\
& & & & & .35 & 70 & .36 & .04 \\
$2(>-1.88)$ & 36 & 341.99 & 21.48 & 3.58 & & & & \\
Total & 92 & 341.44 & 28.07 & 2.93 & & & & \\
\hline
\end{tabular}

*Effect size 
Table 7: $t$-Test of the Difference in P300V Between the Categories of BMD.

\begin{tabular}{cccccccccc}
\hline & \multicolumn{8}{c}{ P300V } \\
\cline { 2 - 8 } BMD & $\boldsymbol{N}$ & $\boldsymbol{M}$ & SD & SE & $\boldsymbol{t}$ & df & $\boldsymbol{P}$ & ES* \\
\hline I $(<=-1.88)$ & 36 & 5.80 & 2.83 & .47 & & & & \\
& & & & & 2.46 & 70 & .005 & .28 \\
$2(>-1.88)$ & 36 & 4.38 & 13.66 & .33 & & & & \\
Total & 92 & 5.28 & 2.66 & .28 & & & & \\
& & & & & & & & &
\end{tabular}

realms of neuropsychosteology, osteoimmunology, and nutrigenomics.

Our findings of a statistically lower bone density and prolonged P300 in patients with high PTH levels may suggest that PTH levels coupled with delayed P300 latency may become putative biological markers of dementia and osteoporosis, and further punctuate the importance of these relationships in the evaluation of overall mental and physical wellbeing. These conclusions support the notion that hyperparathyroidism, dysregulation of bone metabolism, osteopenia, osteoporosis, and its sub-clinical precedents have a more systemic impact on overall health, implicating the opportunity for expanding the scope of therapeutic intervention to augment treatment for other related and potentially serious disorders as well. We await further confirmation of this preliminary study.

\section{Competing interests}

Thomas JH Chen, Amanda LC Chen, Vanessa Arcuri, Mallory Kerner, Anish Bajaj, and Javier Carbajal do not have any competing interests. We declare that we have no conflict of interest. Eric R. Braverman MD, is the director of PATH Medical, where he utilizes both the P300 and TOVA for diagnostic purposes. Kenneth Blum, PhD is the scientific director of the PATH Research Foundation and is a paid consultant, and also the chief scientific advisor for LifeGen, which granted financial support to this research. This study received funding through a grant from a private donor, Rein Narma.

\section{Authors' contributions}

ERB - developed the experimental concept and design, provided editorial contributions, was clinical director of project; TJHC-significant editorial contributions and com-

Table 8: Means and Standard Deviations of PTH by the Two PTH categories.

\begin{tabular}{ccccc}
\hline Category & $\mathbf{N}$ & $\mathbf{M}$ & $\mathbf{S D}$ & $\mathbf{S E}$ \\
\hline $1(<30)$ & 30 & 22.65 & 5.62 & 1.03 \\
$2(>30)$ & 65 & 62.37 & 28.33 & 3.51 \\
Total & 95 & 46.82 & 30.01 & 3.08
\end{tabular}

ments; ALCC - provided editorial comments and literature check for accuracy; VA- editorial and clinical assistance involving data collection, initiation of the first draft of the paper; MK - provided data collection, work on the first draft, editorial contribution, significant additions to the references and background research; $\mathrm{AB}$-provided patient assessment and data collection; JC - provided patient assessment and data collection; DB - patient coordination, editorial comments, and obtained patient consent and regulatory involvement; BWD - responsible for final editorial comments; KB - major co -principle investigator responsible for write -up of manuscript and statistical analysis direction and paper correspondent. All authors read and approved the final manuscript.

\section{Acknowledgements}

The authors would like to thank Path Research Foundation, New York, NY, and LifeGen, Inc. for their financial support. We want to thank the entire staff of PATH Medical and especially acknowledge the grant support of Rein Narma. The authors appreciate the work of Dr. Emanuel Martinez Pons of Brooklyn College, NYC, for his statistical expertise. Dr. Pons was a paid consultant on the project.

\section{References}

I. Dotzenrath CM, Kaetsch AK, Pfingsten H, Cupisti K, Weyerbrock N, Vossough A, Verde PE, Ohmann C: Neuropsychiatric and cognitive changes after surgery for primary hyperparathyroidism. World J Surg 2006, 30(5):680-5.

2. Flicker L, Ames D: Metabolic and endocrinological causes of dementia. Int Psychogeriatr 2005, I 7(SuppI I):S79-92.

3. Washimi Y: Dementia in parathyroid disease. Nippon Rinsho 2004, 62(Suppl):349-52.

4. Braverman ER, Blum K: P300 (latency) event-related potential: an accurate predictor of memory impairment. Clin Electroencephalogr 2003, 34(3): 124-39.

5. Cohen SN, Syndulko K, Rever B, Kraut J, Coburn J, Tourtellotte WW: Visual evoked potentials and long latency event-related potentials in chronic renal failure. Neurology 1983, 33(9): $1219-22$

6. Silver J, Bushinsky D: Harnessing the parathyroids to create stronger bones. Curr Opi Nephrol Hypertens 2004, 13(4):47I-6.

7. DeGroot LJ, Jameson JL: Endocrinology. Volume 2. Fifth edition. Elsevier, Philadelphia; 2006:1534-I538.

8. Rubin MR, Bilezikian JP: Parathyroid hormone as an anabolic skeletal therapy. Drugs 2005, 65(I7):248I-98.

9. Anastasilakis AD, Polyzos SA, Goulis DG, Slavakis A, Efstathiadou Z, Kita M, Koukoulis G, Avramidis A: Endogenous intact PTH is suppressed during Teriparitide (rhPTH I-34) administration in postmenopausal women with established osteoporosis. Endocr J 2008, 55(3):613-6.

10. National Kidney Foundation: K/DOQI clinical practice guidelines for bone metabolism and disease in chronic kidney disease. Am J Kid Dis 2003, 42(Suppl 3):SI.

II. Coresh J, Selvin E, Stevens LA, Manzi J, Krusek JW, Eggers P, Van Lente F, Levey AS: Prevalence of chronic kidney disease in the United States. JAMA 2007, 298( (17):2038-47.

12. Gomella LG, Haist SA: "Chapter 4. Laboratory Diagnosis: Chemistry, Immunology, Serology" (Chapter). Clinician's Pocket Reference: The Scut Monkey, Ile [http://www.accessmedi cine.com/content.aspx?alD=2699454].

13. Mazzaglia PJ, Berber E, Kovach A, Milas M, Esselstyn C, Siperstein AE: The changing presentation of hyperparathyroidism over 3 decades. Arch Surg 2008, I43(3):260-6.

14. National Osteoporosis Foundation: Physicians Guide to Prevention and Treatment of Osteoporosis. Washington DC: National Osteoporosis Foundation; 2003.

15. Hightower L: Osteoporosis: pediatric disease with geriatric consequences. Orthop Nurs 2000, 19(5):59-62. 
16. Chesnut $\mathrm{CH}$ 3rd: Is osteoporosis a pediatric disease? Peak bone mass attainment in the adolescent female. Public Health Rep 1989, 104(Suppl):50-4.

17. Kanji G: $\mathbf{1 0 0}$ Statistical Tests. London, Newbury Park, California: Sage Publications; 1993.

18. Sachs L: Applied Statistics: A Handbook of Techniques. 2nd edition. Springer-Verlag, Berlin, Germany; 1984.

19. Cohen J: Statistical Power Analysis for Behavioral Sciences. 2nd edition. Eribaum Associates, Hillsdale, Nj; 1988.

20. Kirk RE: Statistics: an Introduction 4th edition. Harcourt Brace College Publishers, Fort Worth; 1999

21. Yirmiya R, Goshen I, Bajayo A, Kreisel T, Feldman S, Tarn J, Trembovler V, Csernus V, Shohami E, Bab I: Depression induces bone loss through stimulation of the sympathetic nervous system. Proc Natl Acad Sci USA 2006, 103(45): 16876-8I.

22. Kahl KG, et al:: Bone mineral density, bone turnover, and osteoprotegerin in personality disorder. Psychosom Med 2006 , 68:669-74.

23. Milliken LA, Wilhelmy J, Martin CJ, Finkenthal N, Cussler E, Metcalfe L, Guido TA, Going SB, Lohman TG: Depressive symptoms and changes in body weight exert independent and site-specific effects on bone in postmenopausal women exercising for I year. J Gerontol A Biol Sci Med Sci 2006, 6 I(5):488-94.

24. Ilias I, Alesci S, Gold PW, Chrousos GP: Depression and osteoporosis in men: association or causal link? Hormones (Athens) 2006, 5(I):9-16.

25. Halbreich U, Palter S: Accelerated osteoporosis in psychiatric patients: possible pathophysiological processes. Schizophr Bull 1996, 22(3):447-54.

26. Khudaverdyan DN, Asratyan AA: Effect of the parathyroid hormone-Calcium system on functional activity of the hypothalamus-neurohypophysis complex. Bulletin of Experimental Biology and Medicine 1996, I22(5): 1069-7|

27. Cermik TF, Kaya M, Ugur-Altun B, Bedel D, Berkarda S, Yigitbasi ON: Regional cerebral blood flow abnormalities in patients with primary hyperparathyroidism. Newroradiology 2007 49(4):379-85.

28. Margolin D, Hammerstad J, Orwoll E, McClung M, Calhoun D: Intracranial calcification in hyperparathyroidism associated with gait apraxia and parkinsonism. Neurology 1980, 30(9): 1005-7.

29. Ohtera K, Ishii S, Matsuyama T: Influence of Vitamin D Receptor Alleles on Human Osteoblast-Like Cells. J Born Joint Surg $\mathrm{Br}$ 2000, 83:134-138.

30. Kurbel S, Radi R, Kotromanovic Z, Puseljic Z, Kratofil BA: calcium homeostasis model: orchestration of fast acting PTH and calcitonin with slow calcitriol Med. Hypotheses 2003, 6I(3):346-50.

31. Scillitani A, Guarnieri V, Battista C, De Geronimo S, Muscarella LA, Chiodini I, Cignarelli M, Minisola S, Bertoldo F, Francucci CM, Malavolta N, Piovesan A, Mascia ML, Muscarella S, Hendy GN, D'Agruma L, Cole DE: Primary hyperparathyroidism and the presence of kidney stones are associated with different haplotypes of the calcium-sensing receptor. J Clin Endocrinol Metabl 2007, 92(I):277-83.

32. Hock JM, Fonseca J: Anabolic effect of human synthetic parathyroid hormone-(I-34) depends on growth hormone. Endocrinology 1990, I 27(4): I804-10.

33. White HD, Ahmad AM, Durham BH, Patwala A, Whittingham P, Fraser WD, Vora JP: Growth hormone replacement is important for the restoration of parathyroid hormone sensitivity and improvement in bone metabolism in older adult growth hormone-deficient patients. J Clin Endocrinol Metab 2005, 90(6):337|-80.

34. Walker MD, McMahon DJ, Inabnet WB, azar RM, Brown I, Vardy S, Cosman F, Silverberg S: Neuropsychological Features in Primary Hyperparathyroidism: A Prospective Study. J Clin Endocrinol Metab 2009, 94(6): I95।-I958.

35. Boyce BF, Yao Z, Zhang O, Guo R, Lu Y, Schwarz EM, Xing L: New roles for osteoclasts in bone. Ann N Y Acad Sci 2007 I I 1 6:245-254

36. McCormick RK: Osteoporosis: integrating biomarkers and other diagnostic correlates into the management of bone fragility. Altern Med Rev 2007, I 2(2): | | 3- | 45.
37. Ostrowski K, Rohde T, Zacho M, Asp S, Pedersen BK: Evidence that interleukin-6 is produced in human skeletal muscle during prolonged running. J Physiol 1998, 508:949-953.

38. Lee NK, Sowa H, Hinoi E, Ferron M, Ahn JD, Confavreux C, Dacquin R, Mee PJ, McKee MD, Jung DY, Zhang Z, Kim JK, Mauvais-Jarvis F, Ducy P, Karsenty G: Endocrine regulation of energy metabolism by the skeleton. Cell 2007, I30(3):456-469.

39. Keys A, Brozek J, Henschel A, Mickelsen O, Taylor HL: The Biology of Human Starvation. Minneapolis University of Minnesota Press; 1950.

40. Dulloo A, Jacquet J: Adaptive reduction in basal metabolic rate in response to food deprivation in humans: a role for feedback signals from fat stores. Am J Clin Nutr 1998, 68:599-606.

41. Dulloo AG, Girardier L: Adaptive changes in energy expenditure during refeeding following low-calorie intake: evidence for a specific metabolic component favoring fat storage. Am J Clin Nutr 1990, 52:415-20.

\section{Pre-publication history}

The pre-publication history for this paper can be accessed here:

http://www.biomedcentral.com/1472-6823/9/21/prepub

Publish with Biomed Central and every scientist can read your work free of charge

"BioMed Central will be the most significant development for disseminating the results of biomedical research in our lifetime. "

Sir Paul Nurse, Cancer Research UK

Your research papers will be:

- available free of charge to the entire biomedical community

- peer reviewed and published immediately upon acceptance

- cited in PubMed and archived on PubMed Central

- yours - you keep the copyright
BiolMedcentral 